\title{
RHEOLOGICAL PROPERTIES OF PADDY SOIL UNDER VARIOUS PRESSURE, WATER CONTENT AND TOOL SHAPES
}

\author{
${ }^{1}$ Mari, I.A., ${ }^{1}$ C. Ji, ${ }^{1,2}$ F.A. Chandio, ${ }^{1}$ Chaudhry Arslan, ${ }^{1,2}$ A.A. Tagar and ${ }^{1}$ Fiaz Ahmad \\ ${ }^{1}$ Department of Agricultural Mechanization, \\ Engineering College of Nanjing Agricultural University, Nanjing, China \\ ${ }^{2}$ Department of Farm Power and Machinery, \\ Faculty of Agricultural Engineering, Sindh Agricultural University Tando Jam, Pakistan
}

Received 2013-11-04; Revised 2013-12-10; Accepted 2013-12-14

\begin{abstract}
In this study Burger's four element model was used to analyze rheological parameter of paddy soil of the Southern China. Two types of tool shape include circular shape (with an area of $12.56 \mathrm{~cm}^{2}$ ) and rectangular shape (with an area of $12.56 \mathrm{~cm}^{2}$ ) were use to measure the rheological parameter of paddy soil under different loading pressure $(7.65,10.20$ and $12.75 \mathrm{~kg}$ ) and soil water content $(27$ and $30 \%)$, the test was carried out an indoor soil bin. The results show that the Burger model possesses an excellent prospective for proper representation of the time dependent behavior of a stress-strain time graph curve can well imitate the tool structural change during the soil deformation under different soil water content. Overall results show that, the soil water content has great impact on soil deformation under different loading pressure, where proper tool shapes can control the soil deformation under different pressure. Soil water content on rheological parameter (Em, Ek, $\lambda \mathrm{m}$ and $\lambda \mathrm{k}$ ) were predominantly significant, while loading on rheological parameter (Em, Ek, $\lambda \mathrm{m}$ and $\lambda \mathrm{k}$ ) were not significant. The difference in the mean values among the different levels of M.C and Load has significant difference $(\mathrm{p}=<0.01)$ on rheological parameter in different tool shapes.
\end{abstract}

Keywords: Burger Model, Rheological Properties, Paddy Soil, Soil Water Content

\section{INTRODUCTION}

With the fast development of agricultural mechanization in paddy field, operating machinery needed to deal with the problem, but the customary farming investigation work is still not satisfactory for paddy land. For this purpose, the study of timedependent flow and deformation of a material, expresses its mechanical behavior in terms of different loading pressure, tool shapes, deformation and time or stress, strain and time (Ogunlela, 2011).

Schiffman (1961), first time applied the theory of rheology to work out soil deformation. However many models (Maxwell, Generalized Maxwell and Kelvin model) were applied until now to analysis the soil mechanical behaviors (Changying and Junzheng, 1998).
A detailed and comprehensive model for the mechanical behavior of a paddy soil has to take into account to understand mechanical properties of paddy soil in agricultural production systems in southern China. The four-element burgers rheological model generally can be used to analysis the rheological behavior of paddy soils in south china from last 3 decades (Changying and Junzheng, 1995; 1998; Junzheng and Changying, 1987; 1998; Pan, 1986; Lixin et al., 2010; Mari et al., 2009). The model is en suite to experimental data (stress $\mathrm{x}$ time) by nonlinear regression, to understanding the rheological behavior may provide opportunity to design tools according to the soil behaviors. With the development of mechanization of farming, the design of paddy field machine is become an instant problem (Mainardi and Spada, 2011). But the traditional methods regard the soil Corresponding Author: C. Ji, Department of Agricultural Mechanization, Engineering College of Nanjing Agricultural University, Nanjing, China 
as flexible or mold material, when study the relation between farming parts and soil. Therefore, the basis is study the soil rheology mechanism, to understand the performance and prediction of off-road vehicles. Also to proposed a variety of the predicted vehicle subsidence amount and designed a variety of instruments. Though, these methods and instruments were not considered the time factor, therefore, the stress-strain relationship of time has a strong dependence of paddy field (Liping and Chongyin, 1985). Many scholars soil rheological properties, especially water the field soil rheological properties of the (Liping and Chongyin, 1985; Gupta and Pandya, 1966; Lee 1956; Dey and Basudhar, 2010; Abubakar et al., 2010). But so far, consider the rheological properties of the soil have not yet proposed a practical method to predict the paddy vehicle subsidence amount, nor instruments designed for this purpose.

The aim of this research is to solve the issues of vehicle slippage, soil deformation and soil sublayer compaction. It includes to develop a intelligent meter of soil rheological parameters measured in the field, analysis the rheological parameters in site and determine the best area to explore the response of paddy soils rheological parameters on the impact load and propose a paddy field soil flow the variable characteristic prediction subsidence amount of paddy vehicle.

\section{MATERIALS AND METHODS}

\subsection{Soil Preparation}

A fertile plow layer soil clay loam was collected from Puku Yonling farm of Nanjing agricultural university, China. First soil was sun dried then hammered by electrical hammer after follow this procedure to filled soil bin with paddy soil. Initial soil moisture content was determined then calculated amount of water was sprayed on the entire length of soil to achieve desired experimental soil moisture. After achieving the required condition of experimental soil, rheometer was set up on the soil shown in Fig. 1. Test the mechanical composition of soil samples: Sand; 10\%; Silt; 47\%; clay: 42.2 and $1 \%$ of organic matters.

\subsection{Working Composition of Rheometer}

Rheometry refers to a set of standard techniques that are used to experimentally determine rheological properties of paddy soil under kinetic motion. Rheometer was principled by weight load and quasistatic loading conditions under the settlement amount- time curve. Parts of rheometer are consisted handle pressure, pressure bar, frame, feet, displacement sensors, locking mechanism (Fig. 1-2).

\subsection{Rheological Model of Paddy Field Soil}

Rheology properties deals with deformation of soil and time-dependent flow of moisturized soil and its mechanical performance described as in expressions were deformation, strength and time. Burgers model were described the rheological properties of viscoelastic stress and strain properties (Fig. 3), Junzheng and Changying (1987).

Theoretical described of (Liping and Chongyin, 1985; Gupta and Pandya, 1966; Lee 1956; Dey and Basudhar, 2010; Abubakar et al., 2010): Visco-elastic body of stress and strain analysis and the general media as a row, according to the same basic equation. The difference only lies in the different stress-strain relationship. As long as the stress-strain equation operator set up the basic equations can be solved by the visco-elastic problem (Abubakar et al., 2010).

Burgers model of stress-strain equation for the operator:

$$
\alpha=\frac{\lambda_{1} \frac{\mathrm{d}}{\mathrm{dt}}+\frac{\lambda_{1} \lambda_{2}}{\mathrm{E}_{2}} \frac{\mathrm{d}^{2}}{\mathrm{dt}^{2}}}{1+\frac{\left(\lambda_{1}+\lambda_{2}\right) \mathrm{E}_{1}+\lambda_{1} \mathrm{E}_{2}}{\mathrm{E}_{1} \mathrm{E}_{2}} \frac{\mathrm{d}}{\mathrm{dt}}+\frac{\lambda_{1} \lambda_{2}}{\mathrm{E}_{1} \mathrm{E}_{2}} \frac{\mathrm{d}^{2}}{\mathrm{dt}^{2}}} \varepsilon
$$

If the arithmetical symbol of Equation (1) can be indicated by D, then Equation (2):

$\sigma=\mathrm{D} \varepsilon$

Board will be loaded on the surface of soil samples and weights on the load board, load the plate in Fig. 2 record subsidence of the relationship between volume and time. Plotting the volume of subsidence-the time ( $\mathrm{u}-$ t) diagram and the rheological equation for fitting rheological model can be obtained to calculate the rheological parameters which shown in Fig. 5.

\subsection{Calculation of Rheological Parameters}

By flat-panel set in the semi-infinite elastic body surface settlement schleicher volume formula to determine Equation (3):

$\mu=\frac{\alpha p}{\sqrt{\mathrm{A}}} \cdot \frac{3 \mathrm{~K}+4 \mathrm{G}}{4 \mathrm{G}(3 \mathrm{~K}+\mathrm{G})}$ 


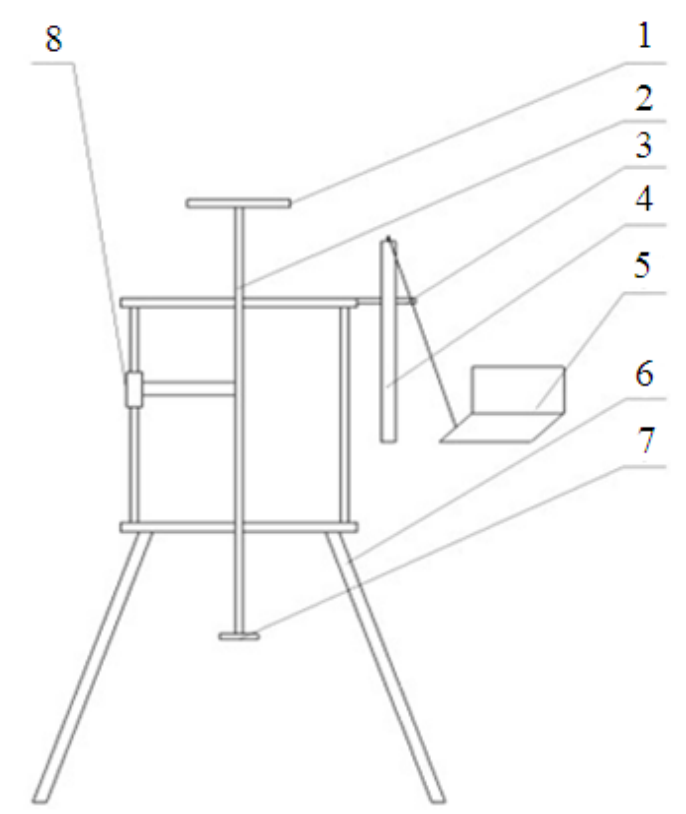

Fig. 1. Schematic view of rheometer parts 1. Loading plate, 2. Loading road, 3. Bracket, 4. Displacement sensor, 5. Computers (including the data acquisition card), 6. Adjestable stand, 7. Probe 8. Locking mechanism

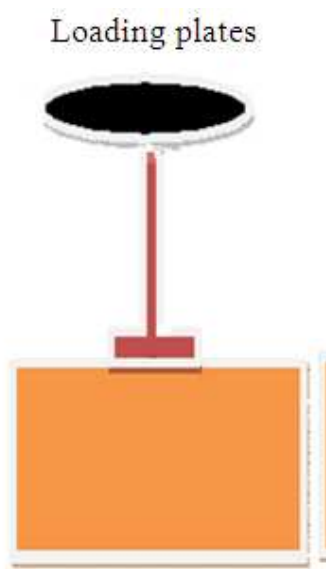

Rectangular shape area $12.56 \mathrm{~cm}^{2}$

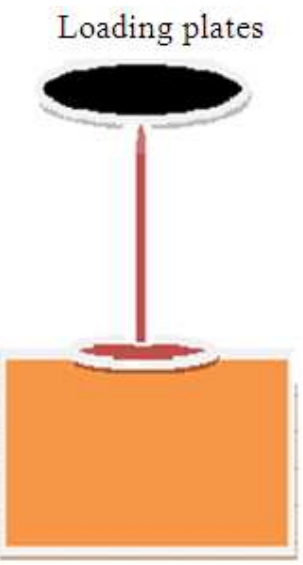

Circular shape area $12.56 \mathrm{~cm}^{2}$
Fig. 2. Schematic view of different tools

China's GM rice paddy soil rheological model, the rheological equation (Gupta and Pandya, 1966; Lee, 1956):

$$
\mathrm{u}=\mathrm{C}\left[\frac{1}{\mathrm{E}_{\mathrm{M}}}+\frac{1}{\mathrm{E}_{\mathrm{K}}}\left(1-\mathrm{e}^{-\mathrm{E}_{\mathrm{K}}^{\mathrm{t} /} \lambda_{\mathrm{K}}}\right)+\frac{\mathrm{t}}{\lambda_{\mathrm{M}}}\right]
$$

where, u-subsidence volume, $\alpha$-Bearing surface shape factor: For circle shape, $\alpha=0.96$; for rectagnular (1:3), $\alpha$ $=0.88$, P-Applied pressure, A-Load area, t-time, KShear modulus, G-compression modulus, $\mu$-Poisson's ratio of soil samples.

$\mathrm{E}_{\mathrm{M}}, \mathrm{E}_{\mathrm{K}}, \lambda_{\mathrm{M}}, \lambda_{\mathrm{K}}-$ Rheological parameters, shown in Fig. 1.

According to the Equation (4), we measured the relationship between the displacement- time on the condition of the under static and dynamic loading at different soil moisture content. Static load conditions, the rheological parameters were used in static load conditions, creep curve were obtained through soil. Data (pressure and subsidence of soil volume) were collected from data logger in the form of excel sheets by computer.

Rheological parameters of the sampling pointed test, Loads are $3 \times 2.554 \times 2.55$ and $5 \times 2.55 \mathrm{~kg}$, where two types of tool shapes were used(circular and rectangular), deforming area of tools were made constant $\left(12.56 \mathrm{~cm}^{2}\right)$ Equation (5):

$\mathrm{C}=\frac{\alpha \mathrm{P}}{\sqrt{\mathrm{A}}}$

Is a constant, with the $\mathrm{C}$ to indicate (4) can be expressed as:

$\mathrm{u}=\mathrm{C}\left[\frac{1}{\mathrm{E}_{\mathrm{M}}}+\frac{1}{\mathrm{E}_{\mathrm{K}}}\left(1-\mathrm{e}^{-\mathrm{E}_{\mathrm{K}} \mathrm{t} / \lambda_{\mathrm{K}}}\right)+\frac{\mathrm{t}}{\lambda_{\mathrm{M}}}\right]$

To obtain the four rheological parameters, must be based on the amount of different subsidence at different times of the four equations. While the Equation (6) were calculated using curve fitting tool in MATLAB programming, because of the large amount of computation to calculate results are shown in Table 1 and 2.

\subsection{Data Acquisition Setup}

Displacement sensor was connected with rheometer (sensor Co., Ltd. Hefei Branch of $\mathrm{Yu}$ WYDC-100L) was controlled by computer program through data acquisition. To get output from displacement sensor an Advantech USB-4716 data acquisition card was a compiled with Lab View 8.2 software. After completing all procedure to save file graphically Microsoft Excel 2007. 


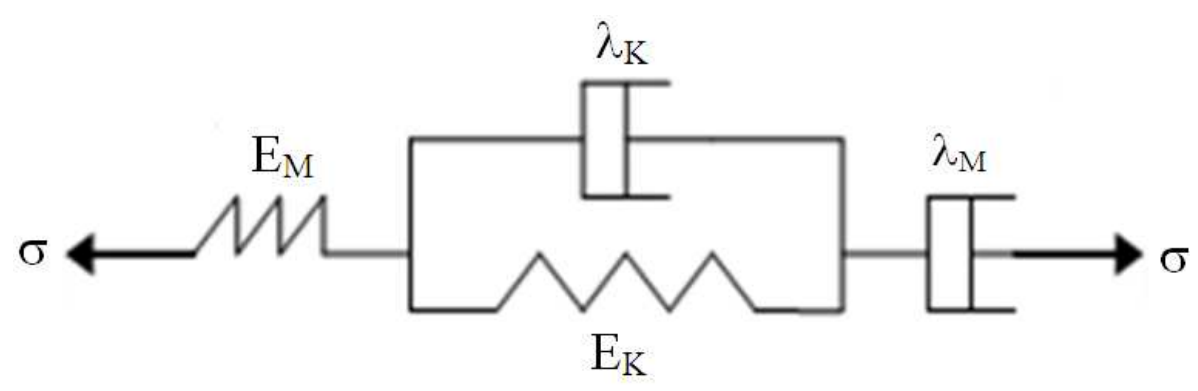

Fig. 3. Burgers model for paddy soil

Table 1. Testing result of rheological parameters circular shape in different water content (27 and $30 \%)$

\begin{tabular}{|c|c|c|c|c|c|}
\hline $\begin{array}{l}\text { Soil water } \\
\text { content }(\%)\end{array}$ & $\mathrm{E}_{\mathrm{M}} / \mathrm{N} / \mathrm{cm}^{2}$ & $\lambda_{\mathrm{M}} / \mathrm{N} \cdot \mathrm{s} / \mathrm{cm}^{2}$ & $\mathrm{E}_{\mathrm{K}} / \mathrm{N} / \mathrm{cm}^{2}$ & $\lambda_{\mathrm{K}} / \mathrm{N} \cdot \mathrm{s} / \mathrm{cm}^{2}$ & $\begin{array}{l}\text { Different } \\
\text { pressure }\left(\mathrm{N} / \mathrm{cm}^{2}\right)\end{array}$ \\
\hline 27 & 145.133 & 1962.50 & 33.75 & 26.31 & 20.32 \\
\hline 27 & 470.280 & 2215.50 & 42.85 & 31.50 & 27.10 \\
\hline 27 & 547.830 & 2773.16 & 46.85 & 40.41 & 33.88 \\
\hline 30 & 137.100 & 1000.15 & 22.11 & 24.74 & 20.32 \\
\hline 30 & 194.890 & 1565.50 & 32.00 & 37.96 & 27.10 \\
\hline 30 & 409.850 & 2001.85 & 43.23 & 47.70 & 33.88 \\
\hline
\end{tabular}

Table 2. Testing result of rheological parameters Rectangular shape in different water content (27 and 30\%)

\begin{tabular}{llllll}
\hline $\begin{array}{l}\text { Soil water } \\
\text { content }(\%)\end{array}$ & $\mathrm{E}_{\mathrm{M}} / \mathrm{N} / \mathrm{cm}^{2}$ & $\lambda_{\mathrm{M}} / \mathrm{N} \cdot \mathrm{s} / \mathrm{cm}^{2}$ & $\mathrm{E}_{\mathrm{K}} / \mathrm{N} / \mathrm{cm}^{2}$ & $\lambda_{\mathrm{K}} / \mathrm{N} \cdot \mathrm{s} / \mathrm{cm}^{2}$ & $\begin{array}{l}\text { Different } \\
\text { pressure }\left(\mathrm{N} / \mathrm{cm}^{2}\right)\end{array}$ \\
\hline 27 & 164.00 & 1072.50 & 16.44 & 14.08 & 16.08 \\
27 & 323.16 & 1380.00 & 12.93 & 17.10 & 18.96 \\
27 & 513.45 & 1569.83 & 11.16 & 21.21 & 23.70 \\
30 & 118.92 & 558.80 & 9.88 & 25.03 & 16.08 \\
30 & 248.49 & 792.75 & 5.79 & 33.62 & 18.96 \\
30 & 396.78 & 966.56 & 3.04 & 41.95 & 23.70 \\
\hline
\end{tabular}

\subsection{Statistical Analysis}

This study was designed as CRD with three replications. To Analysis the rheological properties of paddy soil in different tool shapes, loading rates and different moisture content under control conditions were analyzed by SPSS (ver. 16, SPSS, Inc., Chicago, IL, USA) with ANOVA.

\section{RESULTS AND DISCUSSION}

Two types of tool shapes (circular and rectangular) were used to analysis the response of rheological properties of paddy soil at different pressure (7.65, 10.20 and $12.75 \mathrm{~kg}$ ) and moisture contents $(27$ and 30 $\%)$.The results were computed using Four-element burger rheological model. Soil deformation as a result of circular tool shapes used under different loading pressure at $27 \%$ water content is shown in Figure 4a. Results show, high soil deformation rate was obtained at $12.75 \mathrm{~kg}$ loading pressure (27\% water content) while that was minimum at $7.65 \mathrm{~kg}$ loading pressure. Same trend of soil deformation is shown in Fig. $4 \mathbf{b}-\mathbf{d}$ for circular and rectangular tool shapes under different loading pressure and moisture content. Above results is in agreement with Lixin et al. (2010); Mari et al. (2009) and Changying et al. (2004) which shows the similar trend of soil deformation at different moisture content. So, through the experiments, we can express its mechanical behavior, in terms of different loading pressure. It is also clear from results that a circular shape has high deformation rate then rectangular shape of tool in all experimental conditions.

From Fig. 4a-d we got deformation of the soil, based on that result we can predict the rheological characterization of soil. The rheological parameters of paddy soil in Table 1 and 2 were computed using CF Tool Box Matlab 7.1 to solve Equation number 6 to get rheological parameters of paddy soil under different working conditions. 
Mari, I.A. et al. / American Journal of Agricultural and Biological Sciences 9 (1): 25-32, 2014

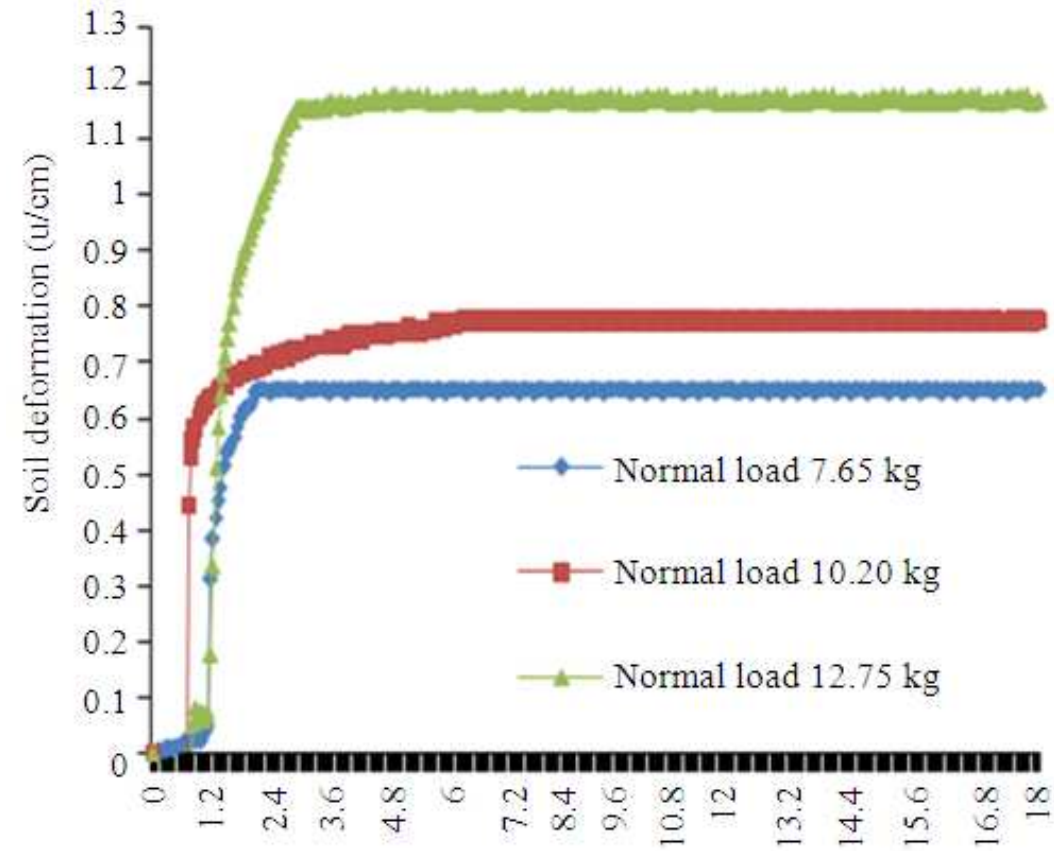

Time (sec)

(a)

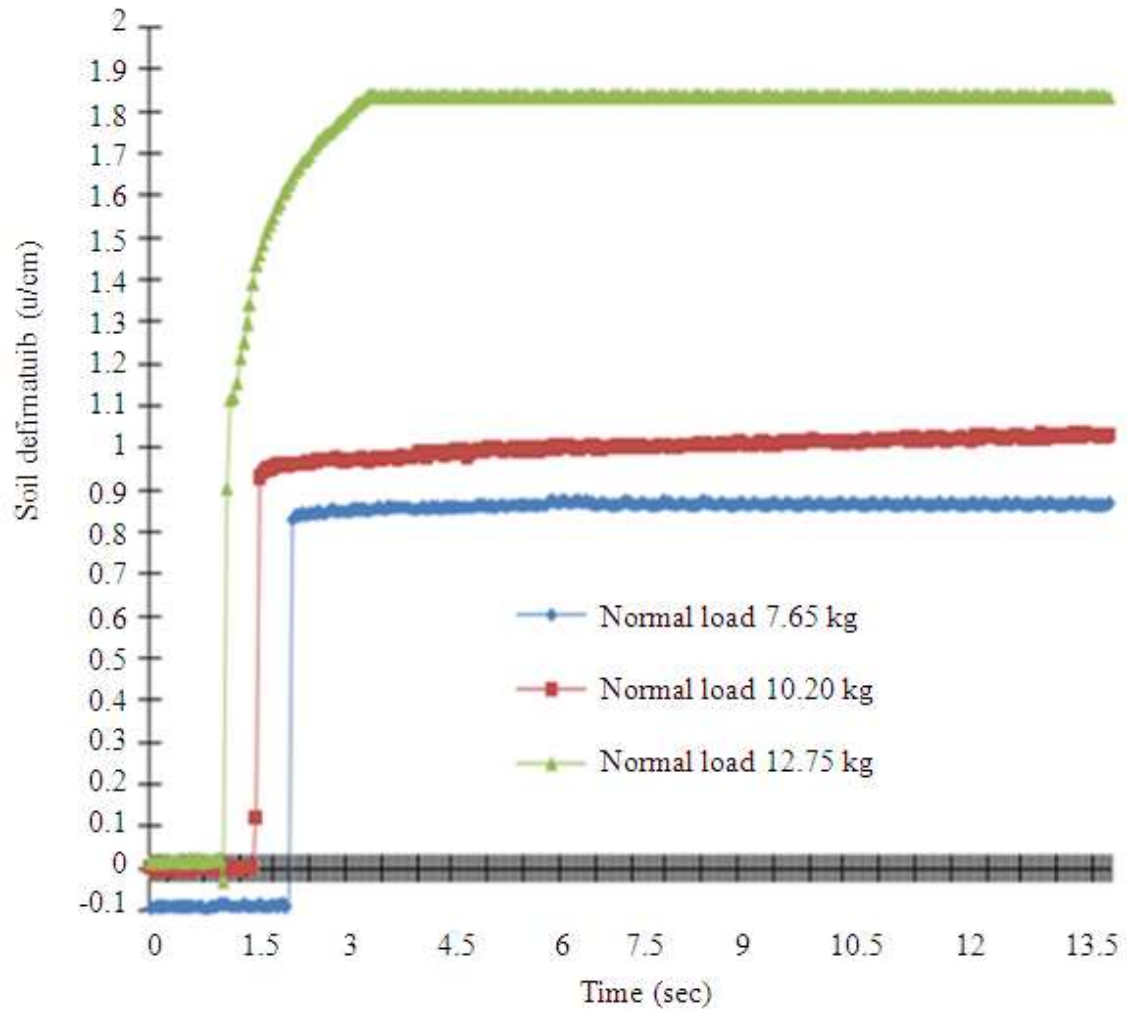

(b) 
Mari, I.A. et al. / American Journal of Agricultural and Biological Sciences 9 (1): 25-32, 2014

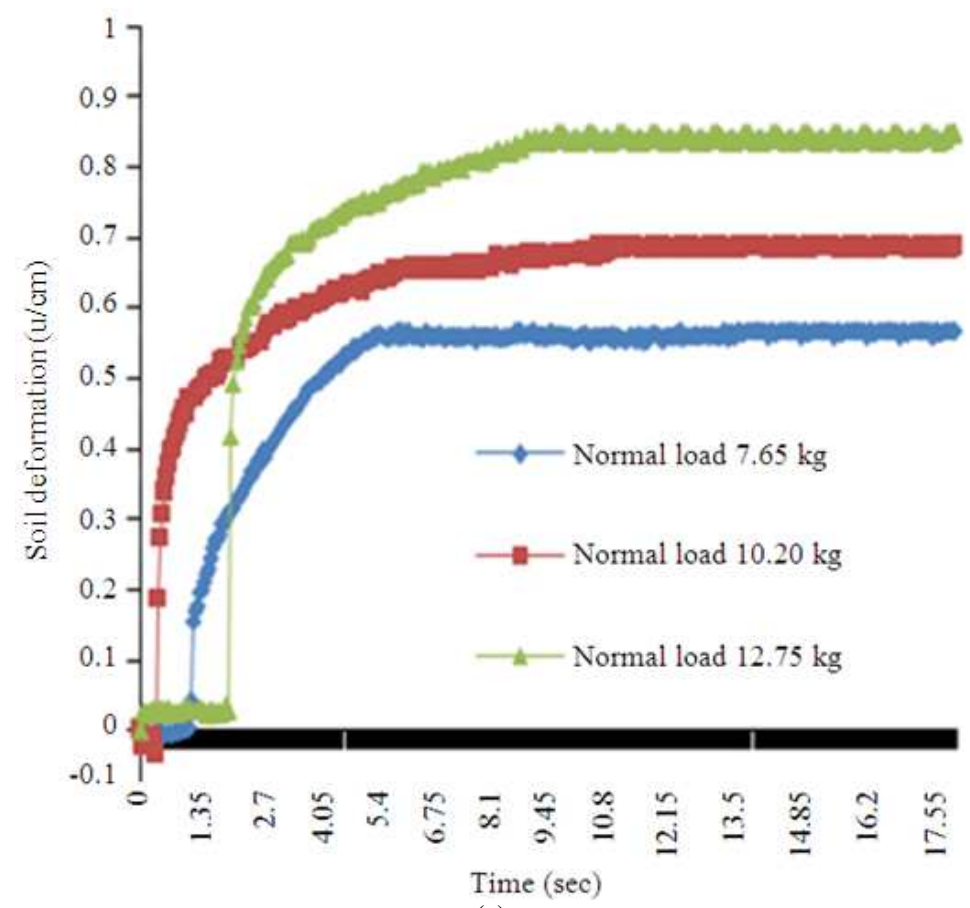

(c)

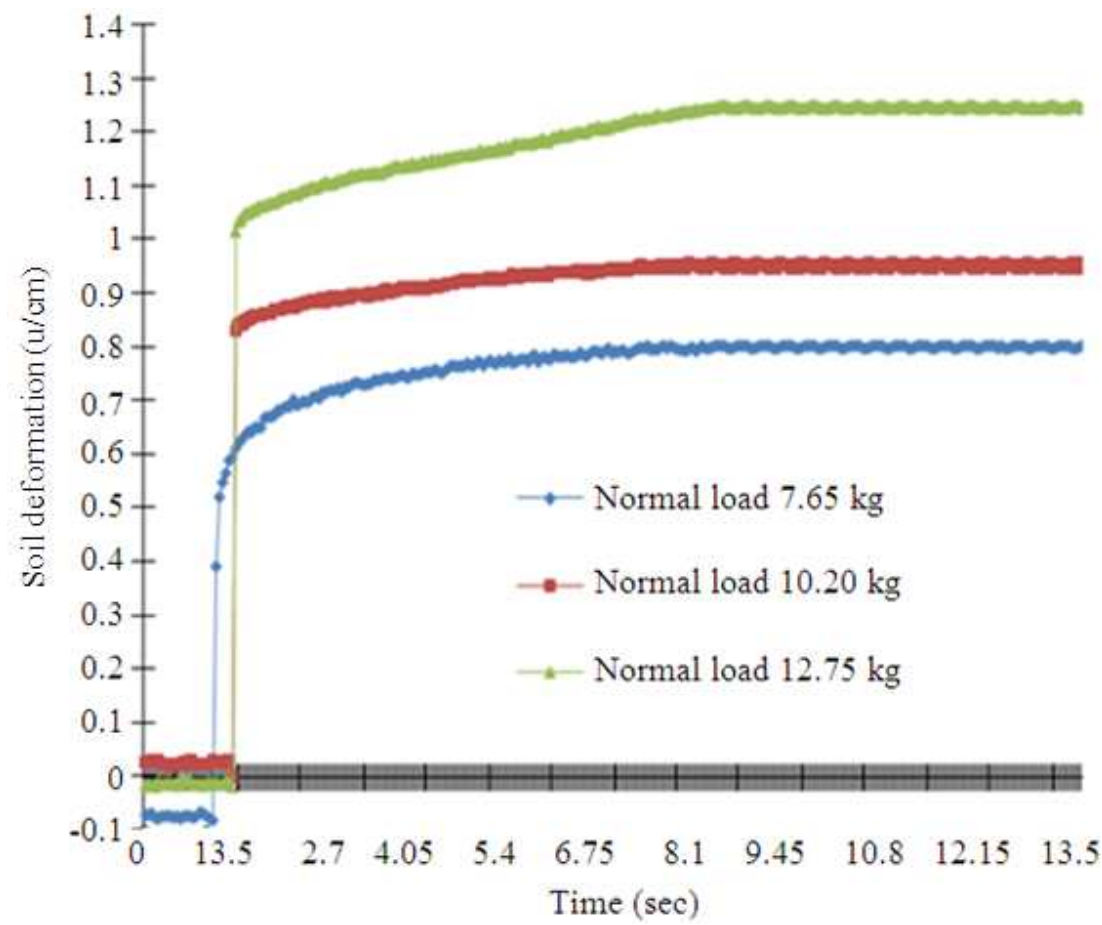

(d)

Fig. 4. The time subsidence curve graphs under different loading pressures at (a) $27 \%$ water content of circular plate (b) $30 \%$ water content of circular plate (c) $27 \%$ water content of rectangular plate (d) $30 \%$ water content of rectangular plate 

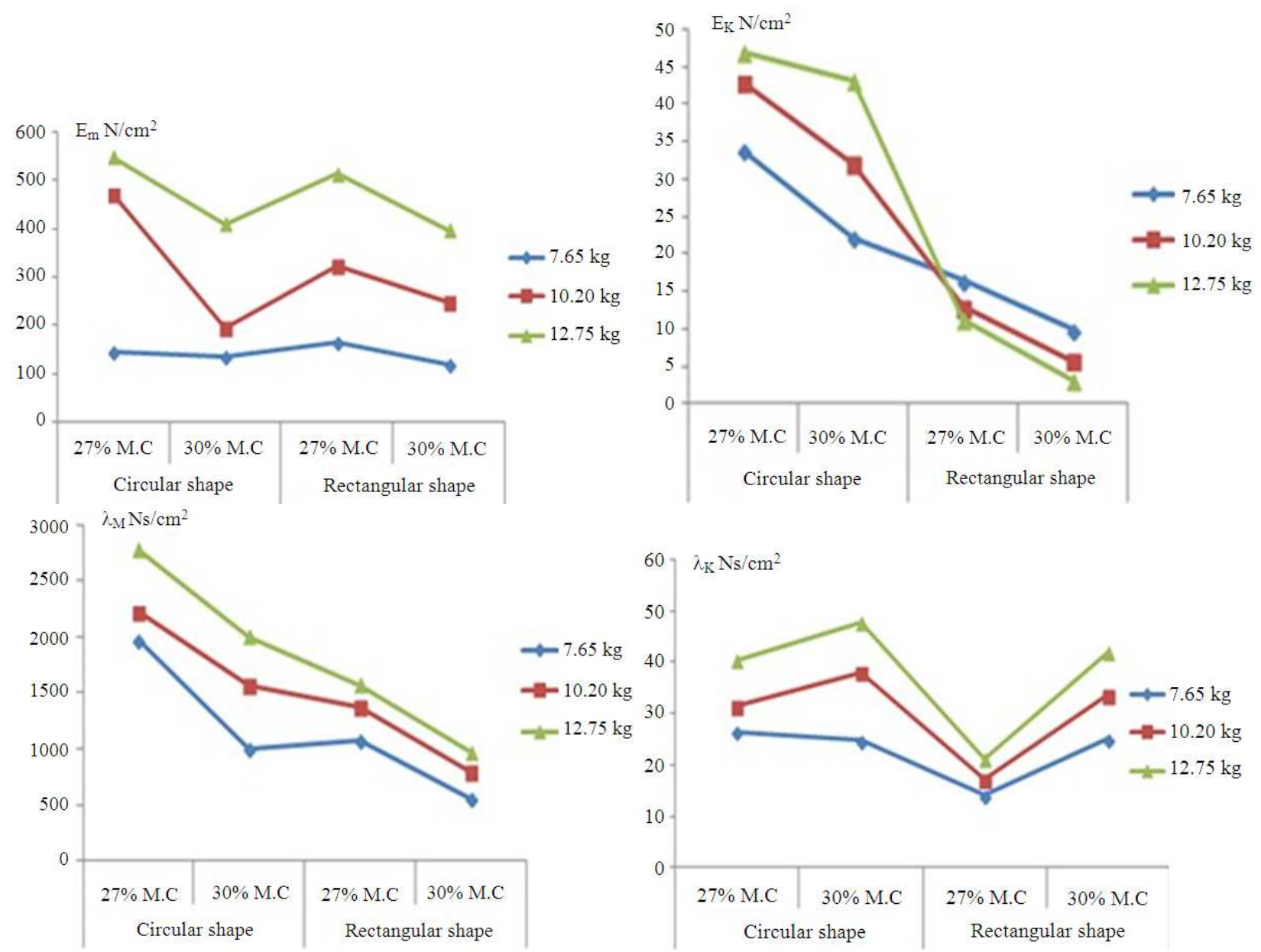

Fig. 5. Rheological parameter under different working parameters $\left(E_{m}, E_{k}, \lambda_{m}\right.$ and $\left.\lambda_{k}\right)$

From Equation (6) in paddy soil stress-strain time illustrates the relationship of four rheological parameters. $\mathrm{u}-\mathrm{t}$ curve with the measured data of the underlying index are close to Equation (1), indicating that this model is more suitable rheological properties of paddy soils of the actual situation Zhiyin and Yunpeng (2008).

From Fig. 5, it was observed that increasing moisture content decreased $\mathrm{E}_{\mathrm{m}}$ value irrespective of tool type and tool shape. The intensity of change was observed to be highest for circular tool at middle load of $10.20 \mathrm{~kg}$ loading rate. Whereas moisture content effect was less for circular tool at the load of $7.65 \mathrm{~kg}$. With soil water content increases, $\mathrm{E}_{\mathrm{m}}, \mathrm{E}_{\mathrm{k}}, \lambda_{\mathrm{m}}$ and $\lambda_{\mathrm{k}}$ equivalents decreased approximately exponentially. Similar trend were also reported by Zejian et al. (1982); Changying et al. (1986) and Mari et al. (2009) in all rheological parameter $\left(\mathrm{E}_{\mathrm{m}}\right.$, $\mathrm{E}_{\mathrm{k}}, \lambda_{\mathrm{m}}$ and $\lambda_{\mathrm{k}}$ ). On the other end, the increasing load has positive effect on $E_{m}$ value in all treatments but was more dominant at less moisture content especially for circular tool as observed by Changying and Junzheng (1998) and Lixin et al. (2010). So far the trend is considered, effect of loading is more uniform for rectangular shape tool as compare to circular shape.

Soil moisture content and tool shapes of paddy soil on rheological parameter were $\mathrm{Em}, \mathrm{Ek}, \lambda \mathrm{m}$ and $\lambda \mathrm{k}$ vales predominantly significant $(\mathrm{p}=<0.01)$; while at same test under different loading rate on rheological parameter Em, $\mathrm{Ek}, \lambda \mathrm{m}$ and $\lambda \mathrm{k}$ values were not significant of paddy soil.

\section{CONCLUSION}

This data obtained from the study indicated that tool shapes, loading pressure and soil moisture content has great impact on the deformation on soil, expresses its 
mechanical behavior in terms of force, deformation, stress, strain and with respect the time curve and also point out the capability of the Burger model in paddy field.

Results showed that, increasing loading pressure soil deformation rate increase significantly at constant water content, in circular and rectangular tool shapes. While, the intensity changes on circular tool has highest as comparing to rectangular tool shape. Where, the impact of soil water contents and tool shapes was found to be significant on rheological parameter Em, Ek, $\lambda \mathrm{m}$ and $\lambda \mathrm{k}$ whereas loading rate were insignificant.

These results are applicable to soil compaction and tillage studies and other agricultural operations including, department to determine the stress state on the pressure-subsidence relations, analyzing of rheological behavior of paddy soil mechanics, exploring rheological paddy soil large deformation failure mechanism and researchers designing tools for paddy soil.

\section{REFERENCES}

Abubakar, M.S., D. Ahmad, J. Othman and S. Sulaiman, 2010. Mechanical properties of paddy soil in relation to high clearance vehicle mobility. Aus. J. Basic Applied Sci., 4: 906-913.

Changying, J. and P. Junzheng, 1995. Chain-paddle driving mechanism and its pull prediction. J. Terramechan., 2: 224-229. DOI: 10.1016/00224898(95)00006-2

Changying, J. and P. Junzheng, 1998. Relationship between bearing capacity and depth of soft layer of paddy fields in South China. J. Terramechan., 35: 225-228. DOI: 10.1016/S0022-4898(98)00025-1

Changying, J., C. Mingnian and P. Junzheng, 2004.The development of paddy soils rheometer in type of dynamic load. Trans. Chinese Soc. Agric. Mach., 35: 88-91.

Changying, J., C. Mingnian and P. Junzheng., 1986. Approach and instrumentation for predicting sinkage of wet land vehicle based on rheological characteristics of paddy soils. Trans. Chinese Soc. Agric. Mach., 17: 21-31.

Dey, A. and P. Basudhar, 2010. Applicability of burger model in predicting the response of viscoelastic soil beds. GeoFlorida, 2010: 2611-2620. DOI: 10.1061/41095(365)265

Gupta, C.P. and A.C. Pandya, 1966. Rheological behavior of soil under static loading. Trans. ASAE, 9: 0718-0724. DOI: 10.13031/2013.40080
Junzheng, P. and J. Changying, 1998. Fuzzy clustering of paddy field soils in South China. J. Terramechan., 35: 21-24. DOI: 10.1016/S0022-4898(98)00009-3

Junzheng, P. and J. Changying., 1987. Prediction of sinkage for wetland vehicles. J. Terramechn., 2: 159-168. DOI: 10.1016/0022-4898(87)90006-1

Lee, E.H., 1956. Stress analysis in materials. J. Applied Phys.

Liping, D. and J. Chongyin, 1985. Changes in waster flow on the paddy field soil subsidence characteristics of. J. Wu Han Inst. Technol., 3: 5057.

Lixin, Z., J. Changying, D. Qishuo and I. Ali, 2010. Viscoelastic computation for creep test of paddy soil. Acta Agric. Zhejiangensis, 22: 509-514.

Mainardi, F. and G. Spada, 2011. Creep, relaxation and viscosity properties for basic fractional models in rheology. Eur. Phys. J. Special Top., 193: 133-160. DOI: 10.1140/epjst/e2011-01387-1

Mari, I.A., J. Changying and Z. lixin, 2009. Effect of moisture content on some rheological properties of paddy soil. Am. Eurasian J. Agric. Environ. Sci., 6: 240-243.

Ogunlela, A.O., 2011. Some rheological and frictional properties of soils and agricultural grains. University of Ilorin.

Pan, J.Z., 1986. The general rheological model of paddy soils in South China. J. Terramechan., 23: 59-68. DOI: 10.1016/0022-4898(86)90014-5

Schiffman, R.L., 1961. Analysis of the displacements of the ground surface due to a moving vehicle. Information for the Defense Community.

Zejian, L., Q. Yanqiao and P. Junzhen., 1982. Rheological characteristics of paddy-field soils in China. Agricultural Machinery School Newspaper.

Zhiyin, W. and L. Yunpeng, 2008. Rock Rheology Theory and Numerical Simulation. 1st Edn., Scientific Publishing, Beijing. 